\title{
\#i

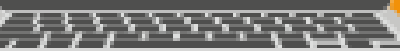 \\ O USO DO WHATSAPP, GOOGLE DRIVE, E-MAIL, E MOODLE NA COORDENAÇÃO DE UMA ESCOLA PÚBLICA
}

\section{Maria Aparecida Rondis Nunes de Abreu}

(Escola Municipal Prof. Licurgo de Oliveira Bastos - Brasil - rondismaria@gmail.com)

Erlinda Martins Batista

(Universidade Federal de Mato Grosso do Sul - Brasil - erlindabatista@gmail.com)

\section{Luziety Adalgisa Gimenez Loiola}

(Escola Municipal Prof. Licurgo de Oliveira Bastos - Brasil - luziloiola@gmail.com)

\section{RESUMO}

Este artigo relata o uso do WhatsApp, e-mail, Google Drive e Moodle como ferramentas de comunicação entre coordenação pedagógica e docentes na Escola Municipal Professor Licurgo de Oliveira Bastos em Campo Grande, MS. O diálogo virtual amplia a gestão. Semanalmente, um docente encarrega-se de compartilhar o planejamento para análise do coordenador e docentes adaptando-o às turmas. Vislumbra-se a reflexão dos professores no contexto educacional para que surjam novas pesquisas aprofundando o uso das TICs e que órgãos governamentais invistam significativamente em prol da melhoria da infraestrutura fundamental ao uso destas ferramentas virtuais e na formação continuada dos professores e coordenadores.

Palavras-chave: Moodle, WhatsApp, Coordenação Pedagógica.

\section{INTRODUÇÃ̃O}

A contemporaneidade caracteriza-se por ser uma era em que as ferramentas digitais têm um papel transformador no fazer pedagógico nas escolas. As tecnologias como o WhatsApp, email, Google Drive, ambiente virtual Moodle, são apresentadas nesse artigo, com o objetivo de discutir a experiência de trabalho docente e da coordenação pedagógica com o uso de 


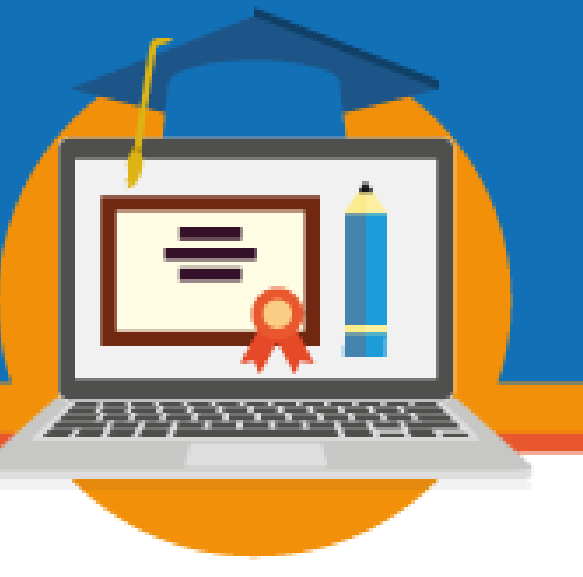

tecnologias no âmbito de uma escola pública municipal. Trata-se de um diálogo ousado que envolve todo o coletivo escolar. Nesse contexto, a Escola Municipal Prof. Licurgo de Oliveira Bastos, doravante denominada EM Prof. Licurgo, desde 2012, vem por meio da plataforma Moodle procurando inovar no diálogo entre coordenação e docentes. No ano de 2017 a Coordenação Pedagógica do $3^{\circ}$ ano do Ensino Fundamental disponibilizou o uso do Google Drive, e-mail, WhatsApp e Moodle para os professores postarem o planejamento das aulas, as atividades, filmes, livros e outras possibilidades de ministrar aula.

A equipe do $3^{\circ}$ ano do Ensino Fundamental, formada por 6 professoras com licenciatura em Pedagogia que ministravam aulas de Língua Portuguesa, Matemática, História e Geografia, sendo; 2 professoras com licenciatura em Ciências, 2 professores com licenciatura em Arte e 2 professores com licenciatura em Educação Física.

A cada semana um professor Pedagogo ficava responsável por postar o planejamento semanal no Google Drive, bem como, atividades que seriam desenvolvidas ao longo da semana, compartilhando-as no Moodle para que todos os membros da equipe do $3^{\circ}$ ano tivessem acesso a esse documento. Desta maneira, todos os professores tinham oportunidades de desenvolver o mesmo planejamento adequando-o à sua turma e dando sugestões para que o plano de aula atingisse de fato os aspectos favoráveis ao ensino e aprendizagem dos alunos.

Concomitantemente, os demais professores, isto é, das outras disciplinas postavam o planejamento mensal da mesma forma compartilhando com seus pares. E, por sua vez, a coordenadora pedagógica fazia as intervenções necessárias, sugerindo textos, filmes, aulas nos laboratórios de ciências, matemática e informática, aulas na biblioteca e outros recursos que a escola disponibiliza para os professores utilizarem em suas aulas. Deste modo, o professor tinha praticamente um mês ou um mês e meio para estudar e planejar.

Entre outros objetivos, destacam-se aqui os objetivos: geral e específicos do presente relato:

1.1 Objetivo geral:

- Relatar a experiência pedagógica com o uso do WhatsApp, e-mail, Google Drive, ambiente virtual Moodle, nas atividades docentes da Escola Municipal Professor Licurgo. 


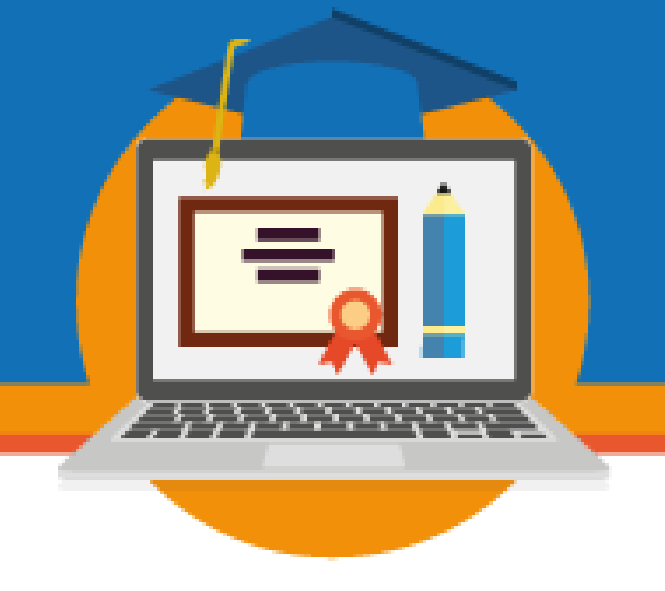

\subsection{Objetivos Específicos:}

- Refletir sobre o uso das ferramentas tecnológicas no contexto de uma escola municipal;

- Discutir os benefícios do uso das ferramentas tecnológicas utilizadas no contexto da escola citada. Kenski (2012) situa as relações existentes entre os avanços tecnológicos e as alterações de seus usos nas sociedades em diferentes épocas, como pautadas pelo conhecimento, e pelo poder das tecnologias. Para que essa inovação na forma de planejar fosse incorporada pelo corpo docente da escola mencionada, a Coordenadora Pedagógica oportunizou formações continuadas sobre a utilização do e-mail, WhatsApp, Google Drive e Moodle.

O processo de socialização do planejamento foi lento em razão de os professores necessitarem compreender que aquela nova proposta de trabalho em equipe realmente traria benefícios para o grupo, e sentirem a confiança em seus pares de que planejariam e postariam realmente de acordo com o cronograma realizado pelo grupo do $3^{\circ}$ ano.

A Coordenação Pedagógica teve como parceira a coordenadora de tecnologia para possibilitar as formações e também o acesso ao uso das ferramentas tecnológicas que a escola disponibiliza para esse grupo escolar. As formações foram oferecidas fora do horário de trabalho, na modalidade presencial e a distância, sendo que os professores recebiam o material online por meio das ferramentas digitais mencionadas no início do texto.

Considerando que essas experiências continuam na escola em questão e que a ideia é implementá-las a partir de novos estudos e pesquisas, justifica-se o presente relato e os estudos vindouros.

\section{METODOLOGIA}

O relato apresentado nesse artigo foi fundamentado nas premissas da pesquisa qualitativa em educação conforme as ideias de Lüdke e André (1986) sobre a necessidade de 


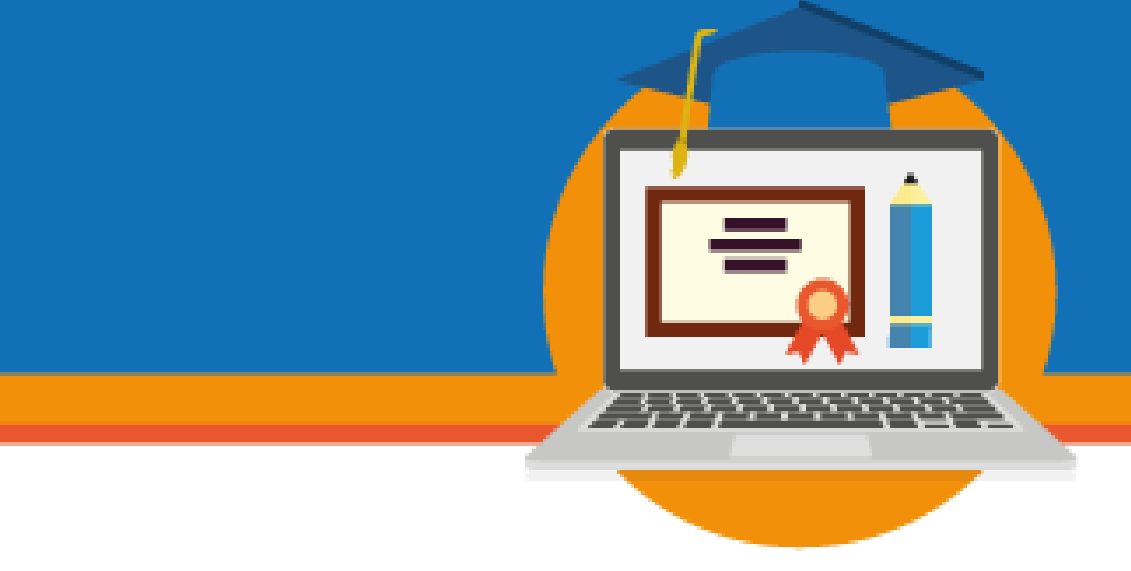

divulgar as experiências educativas favoráveis no âmbito escolar, de modo que tal relato possa contribuir para o meio científico e para novas decisões educacionais no contexto da gestão escolar e governamental.

A precaução para esse tipo de pesquisa é mostrar a complexidade do ambiente escolar, o que a escola oferece aos educandos e o que eles trazem do seu cotidiano. O pesquisador necessita ficar atento em razão de ter várias fontes de pesquisa, com diferentes tipos de sujeitos e cruzar esses dados para que sua pesquisa seja a mais fiel possível e os resultados possam realmente trazer benefícios à comunidade científica e com isso o ensino e aprendizagem possam ser efetivados com excelência nas escolas.

A EM Prof. Licurgo, localiza-se em Campo Grande - MS, e oferece Ensino Básico nas modalidades Educação Infantil e Ensino Fundamental. São 29 salas de aula, no período matutino atendendo alunos da Educação Infantil ao $5^{\circ}$ ano do Ensino Fundamental, e no período vespertino 29 salas de aula, atendendo 4 salas da Educação Infantil e 25 salas de Ensino Fundamental, sendo que, 19 salas são de $6^{\circ}$ ao $9^{\circ}$ ano. A Escola Licurgo atende 1.800 estudantes em dois turnos (matutino e vespertino) e conta com a colaboração de 140 funcionários entre professores e técnicos-administrativos.

Segundo Severino (2007) a escrita científica deve ser clara sobre o objeto de estudo, e nesse sentido, destaca-se que a experiência com o uso dos recursos tecnológicos já mencionados, que iniciou-se em 2012, tendo sido ampliada em 2014 e revitalizada em 2015 a partir da oferta de atividades e interações por meio do Google Drive e WhatsApp.

\subsection{ESPAÇO ESCOLAR, TECNOLOGIA E FORMAÇÃO CONTINUADA}

O espaço escolar na contemporaneidade em alguns casos, como o caso da EM Prof. Licurgo de Oliveira Bastos está dotado de novas ferramentas advindas de tecnologias que propiciam novas maneiras de aquisição do conhecimento e de troca de informações entre os membros da equipe escolar. 
O Sistema Moodle, segundo Nakamura (2009) foi criado em 2001 e consiste de uma plataforma virtual de aprendizagem contínua, baseando-se no sócio-interacionismo, no qual o conhecimento é construído a partir da interação por meio do diálogo coletivo, sendo tal coletivismo, denominado de trabalho colaborativo e coletivo conforme ideias de Kenski (2012). A formação continuada nesse ambiente virtual é completa, visto que os participantes constroem ativamente os artefatos por meio de textos, vídeos, imagens, individualmente ou coletivamente, para que todos os usuários que tenham acesso a esse ambiente vejam ou utilizem no seu fazer pedagógico. Neste sentido, os participantes interagem entre si por meio de chats, fórum e-mail e muitos outros recursos que são oferecidos nessa plataforma virtual de aprendizagem.

O e-mail revolucionou a forma de comunicação das pessoas em todos os lugares do mundo e, conforme Tussi (2006) a primeira mensagem entre dois computadores foi trocada em 02 de outubro de 1971. Assim, desde então, a utilização dessa ferramenta tecnológica veio sendo aprimorada e disponibilizada para os usuários, visto que a comunicação por meio do $e$ mail é mais barata do que por telefone. Por essa razão, a referida escola passou a adotar essa ferramenta no seu cotidiano escolar.

O Google Drive, segundo Balbino et al (2016), baseia-se no conceito de "computação em nuvem", ou seja, o internauta poderá armazenar seus arquivos por meio deste serviço e acessá-los a partir de qualquer computador ou dispositivo compatível. Logo, podem-se compartilhar arquivos, torná-los públicos ou não, sendo que os arquivos quando compartilhados, dependendo da situação do professor que o utiliza, ele pode ter permissão ou não para sua edição e comentários. Na Escola Licurgo há professores, principalmente os educadores dos $3^{\circ}$ anos, que já estão familiarizados com essa ferramenta tecnológica, uma vez que ela veio para dinamizar o fazer pedagógico do grupo escola.

O uso do WhatsApp como ferramenta pedagógica na referida escola vem acontecendo desde 2015, e segundo Santos (1997) com o advento da globalização, com a revolução tecnológica que está acontecendo no mundo contemporâneo, faz se necessário utilizar de maneira científica toda essa tecnologia que se tem no âmbito escolar. 


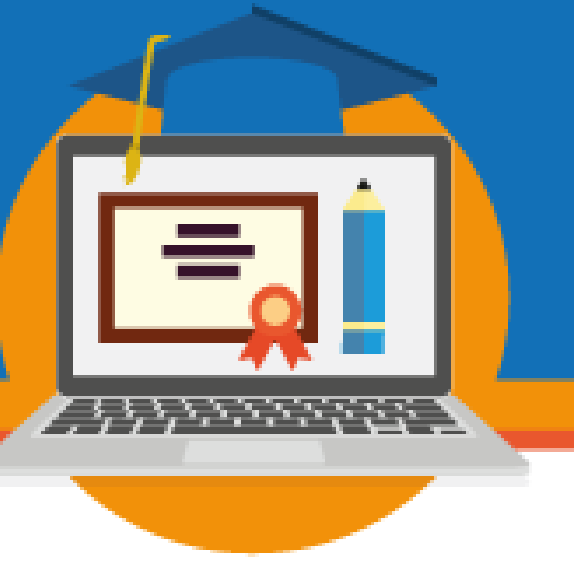

Entende-se que a formação contínua dos professores e demais membros da escola deve ser constante, e na EM. Prof. Licurgo, as formações acontecem quinzenalmente e de acordo com a necessidade do grupo dessa escola. Esta necessidade e conscientização que originou-se na percepção de que na época em que se vive, é fundamental e inegável o uso das ferramentas tecnológicas em prol de um processo de ensino e aprendizagem eficazes.

Em análise geral do espaço escolar, observa-se que as mudanças diárias nas condições sociais e históricas da sociedade contemporânea levam os sujeitos ao aperfeiçoamento da práxis pedagógica.

\subsection{APORTE SÓCIO-HISTÓRICO - BASE AO RELATO EDUCACIONAL}

As leituras de Freitas $(2002,2008,2009)$ têm importante papel na definição do método de trabalho neste relato de experiência. Compreender a nuance histórico-social e cultural relativa ao objeto e encontrar o método adequado ao relato em estudo, que se propõe, não se constitui tarefa fácil para o pesquisador. A teoria positivista que, no passado, ancorava as pesquisas no país, principalmente nas áreas das ciências exatas e naturais, tem sido criticada por pesquisadores das ciências humanas que procuram realizar uma investigação imbuída das perspectivas de mudança da realidade. A preocupação com o método é, portanto, fundamental ao realizar-se um relato de experiência ou mesmo uma pesquisa que contribua para a área educacional e para a sociedade como um todo.

Para discutir os processos interativos nas práticas de professores que atuam em ambientes virtuais de aprendizagem, utilizou-se, como pressuposto teórico-metodológico, a perspectiva do materialismo dialético, na abordagem histórico e cultural ${ }^{1}$, da escola de Vygotsky (2003). Nessa abordagem, a constituição social do sujeito ocorre a partir das relações sociais que ele estabelece no meio em que vive, começando no seio da família e, adiante, ampliando para outros núcleos sociais, como o da escola, por exemplo. As interações virtuais

\footnotetext{
1 Trata-se do referencial teórico-metodológico fundamentado na Psicologia histórico-cultural estudada por Vygotsky (2003) e seus colaboradores, conforme explicam Morettini e Urt (2010).
} 
ensejam atos em constantes transformações, não apenas devido às condições específicas em que se situam, isto é, em ambientes virtuais de aprendizagem coletiva, mas, em particular, pelo caráter de mudança que envolve os recursos tecnológicos existentes na práxis pedagógica, conforme Batista e Gobara (2015).

A retratação da realidade e os obstáculos concretos aí vividos requerem um olhar histórico-cultural, no sentido não apenas de observar a realidade, mas manter a concretude do fenômeno. Nesse método, ao mesmo tempo em que não se limita à simples descrição, a explicação dos fatos representa um ponto relevante porque possibilita ao pesquisador enxergar os obstáculos e as mudanças que se fazem necessárias, diante do concreto que se impõe (FREITAS, 2002, p.06).

Os paradigmas que orientaram o fazer científico - e, portanto, as pesquisas educacionais no Brasil -, segundo Freitas (2002), abrangem, inicialmente, três linhas de pensamento: 1) o positivismo, que predominou até os anos de 1970 e que ainda tem relevância nas áreas duras ou das exatas; 2) o interpretativista, que surge entre as décadas de 1960 e 1970, e 3) o crítico, que tem se afirmado desde os anos de 1980 com a valorização do pensamento de Marx (1999) na Crítica da Economia Política, e de Vigotsky (1991) com a Formação Social da Mente, Pensamento e Linguagem e Obras escolhidas.

A utilização desses paradigmas, como instrumentos ou ferramentas de apoio ao pensamento, mostrada por Freitas (2002) resgata ao pesquisador as bases necessárias não apenas para as análises do fenômeno, mas para ir além dos resultados, dos debates, e realizar uma intervenção mais concreta na realidade relatada. Realidade que enfoca, no relato em questão, a interação nos ambientes virtuais de aprendizagem e as interações nas práticas educacionais que se fazem neles.

Freitas (2002) afirma que, na compreensão da realidade concreta investigada, pode-se até fazer um ponto de contato entre as abordagens da teoria crítica e o paradigma interpretativista. Na concepção do paradigma interpretativista, a finalidade da investigação relaciona-se à compreensão e à interpretação e tem-se a convicção de que o real não é apreensível, mas uma construção dos sujeitos que entram em relação com ele. Entretanto, ao 


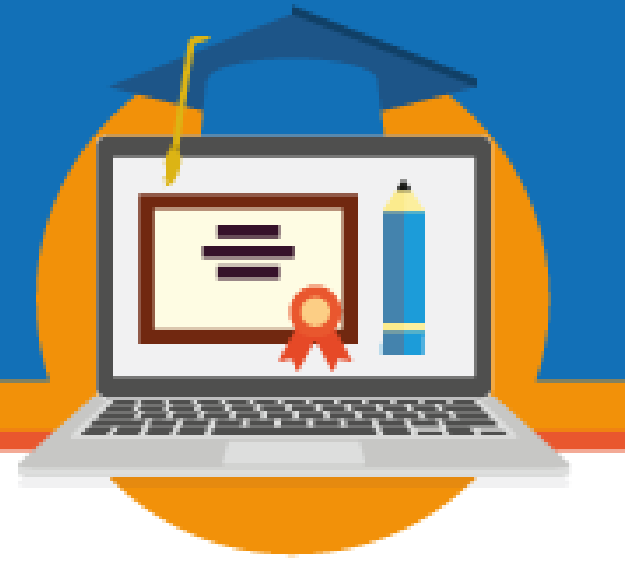

aproximar-se desse paradigma, o pesquisador deve ter clareza do seu papel, o qual vai além da interpretação, envolvendo também uma ação de construção cognitiva que surge do conhecimento da realidade observada como ressalta Freitas (2002, p. 10):

O papel do pesquisador não consiste, pois, em simplesmente descrever e compreender a realidade, como quer o paradigma interpretativista, mas em construir um conhecimento que desvele a realidade a partir dos textos que emergem nas interlocuções da situação de pesquisa. Daí que o encontro dos sujeitos se faz não só no plano individual como acontece no paradigma interpretativista, mas, sobretudo social, um encontro de culturas, de contexto.

No pensamento sócio-histórico, o papel do pesquisador abrange a adoção de uma postura que retrata a realidade em que se insere o objeto de pesquisa e as relações do sujeito com esse objeto.

Concorda-se, neste sentido, com Freitas (2002), que vê, no paradigma sócio-histórico, uma mudança conceitual, isto é, uma nova visão de mundo. Freitas (2002) menciona que o pensamento Vygotskyniano proporciona essa mudança paradigmática, ao fundamentar as suas teorias no materialismo histórico-dialético em razão de suas insatisfações e críticas aos reducionismos dos pensamentos empiristas e idealistas. Nesse parâmetro teórico, o fazer pesquisa em ciências humanas torna-se mais exigente, na medida em que a coerência e a ética são exigidas na utilização dos instrumentos metodológicos de coleta e análise dos dados, assim como na elaboração do texto de discussão dos resultados. Outro estudo de Freitas (2002) conclui que:

a abordagem sócio-histórica ao compreender que o psiquismo é constituído no social num processo interativo possibilitado pela linguagem, pode permitir o desenvolvimento de alternativas metodológicas que superem as dicotomias objetivo/subjetivo, externo/interno, social/individual (Freitas 2002, p. 5).

Considerando que as interações em ambientes digitais e virtuais de aprendizagem são uma constante no mundo atual, se concretizam na realidade da Escola Municipal Prof. Licurgo, e que a teoria interacionista de Vygotsky se adequa como base para esse relato dos fazeres 


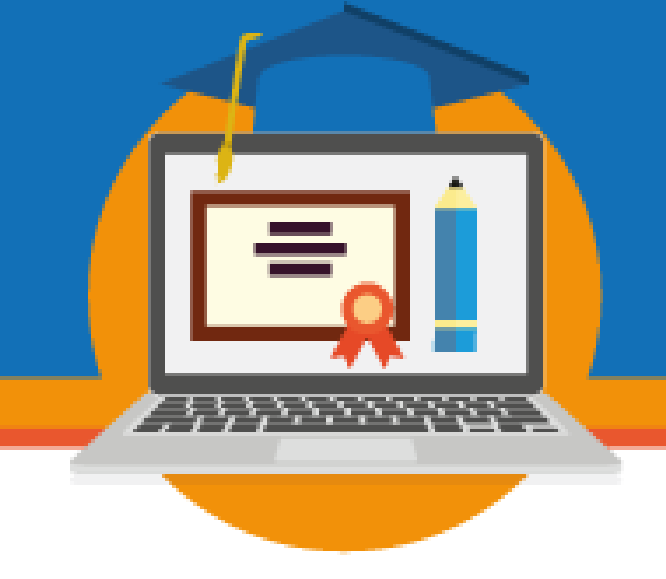

pedagógicos, justifica-se este estudo. No próximo item apresenta-se uma interlocução com as ideias Vygotskianas a fim de se fundamentar teoricamente o presente trabalho.

\section{VYGOTSKY E A TEORIA INTERACIONISTA DE APRENDIZAGEM}

O presente referencial teórico baseia-se nos pressupostos da dialética materialista, sob os quais se discute a relação entre o sujeito, o objeto e o seu meio, o que requer, nesse caso, uma compreensão do homem real e concreto na base do pensamento dialético.

Vygotsky (2003) explica que a dialética no processo educativo caracteriza-o como um processo composto por lutas complexas e confrontos no nível da natureza psicológica do sujeito. Os embates de natureza psicológica do sujeito são úteis na experiência social e nas relações dialéticas, interativas, portanto, com o meio social e histórico.

Vygotsky (1896-1934) nasceu em 05 de novembro de 1896, na cidade de Orsha, no nordeste de Minsk, na Bielo Rússia. Formou-se primeiramente advogado e filólogo, com especialização em literatura no ano de 1917. Nessa época já havia contribuído com vários trabalhos de crítica literária. Posteriormente, após a revolução russa de 1917, formou-se em Psicologia. Portanto, ele foi um psicólogo soviético, cuja formação multidisciplinar o levou a estudar a psicologia infantil e suas implicações pedagógicas. Foi reconhecido como o pioneiro da Psicologia do Desenvolvimento. Após trabalhar com deficientes mentais na Rússia, estudou medicina com o objetivo de compreender os problemas neurológicos das pessoas com esse tipo de deficiência.

As obras de Vygotsky foram primeiramente influenciadas pela situação pós- revolução de 1917 na Rússia. Em segundo lugar, a influência das ideias de Marx contribuiu para a estrutura de seu pensamento materialista histórico e dialético. A obra O Capital de Marx, inspirou Vygotsky, em sua busca por compreender o pensamento humano a partir da ideia de que mudanças históricas na sociedade e na vida material produzem mudanças na natureza humana (consciência e comportamento).

Em sua primeira obra: “A linguagem e o pensamento” Vygotsky (2001) enfatiza as origens sociais da linguagem e do pensamento, e seguiu a orientação dos sociólogos franceses, 
tendo assim, se tornado o primeiro psicólogo moderno a sugerir os mecanismos pelos quais a cultura torna-se parte da natureza de cada pessoa.

Ao propor que sua teoria fosse entendida a partir da teoria marxista da história da sociedade humana, lançou a base fundamental para uma ciência comportamental unificada. Até aí a psicologia era vista como uma ciência natural (dentro de um pensamento cartesiano) que explorava apenas o físico, sendo os estudos da alma e das funções cerebrais superiores relegados à filosofia. (VYGOSTKY, 2003, p. 09-10).

Vygotsky (2003) dedicou seus estudos à pedologia, ciência que estuda o desenvolvimento humano articulando os aspectos antropológicos, psicológicos e biológicos. Suas teorias foram influenciadas pelo pensamento marxista e desenvolvidas num contexto de escola sócio-histórica. Para Vygotsky (2003) desenvolvimento e aprendizagem são processos interativos. A aprendizagem na criança se realiza em um meio específico a partir de sua interação com o professor, com o meio, e com outras crianças. Nessa teoria, o professor é o organizador do meio educativo e a criança educa-se a si mesma a partir da interação com o professor e com os membros do grupo social, histórico e cultural do qual faz parte.

A teoria interacionista de aprendizagem de Vygotsky (1991) foi escrita entre os anos de 1920 e 1934, entretanto, considera-se atual porque nela esse autor apresentou os resultados de suas pesquisas os quais mostraram como as interações contribuíam para a aprendizagem em seus grupos de estudos. Seu grupo de estudo também coordenado por Luria realizou pesquisas sobre a aprendizagem e o desenvolvimento a partir das interações entre crianças que já possuíam o conhecimento para a solução de determinado problema e crianças que ainda não tinham dominado o conhecimento para a solução do problema.

Para Vygotsky (2003), o indivíduo forma o seu comportamento em decorrência de suas singularidades e dos fatores biológicos e sociais de seu próprio desenvolvimento. $\mathrm{O}$ fator biológico determina as reações herdadas, em cujos limites o organismo desencadeia o sistema de reações aprendidas.

O que seriam as reações aprendidas? Vygotsky (2003) chama as reações aprendidas de um novo sistema de reações. E, sobre esse novo sistema de reações, ele enfatiza: “[...] esse novo 
sistema de reações é totalmente determinado pela estrutura do ambiente no qual o organismo cresce e se desenvolve. Por esse motivo, toda educação tem inevitavelmente um caráter social" (VYGOTSKY, 2003, p. 75).

Nesses parâmetros, tanto a educação infantil quanto a do jovem e também do adulto contribuem para a formação da identidade histórica e social do sujeito. As experiências vivenciadas pelos estudantes em situações educativas são fundamentais para sua formação. Ainda no que concerne às experiências do sujeito em relação à educação, o autor argumenta: "A própria experiência é o único educador capaz de formar novas reações no organismo" (idem).

Segundo essa visão, a experiência pessoal do educando é a "Principal base do trabalho pedagógico" (VYGOTSKY, 2003, p. 75). Inicialmente, essa afirmação Vygotskyniana parece isolar o papel do professor, ao valorizar a experiência do estudante. Observe que o seu destaque para a experiência do estudante é no sentido de que: "Do ponto de vista científico, não se pode educar a outrem [diretamente]. [...] Só é possível educar, a si mesmo, isto é, modificar as reações inatas através da própria experiência” (VYGOTSKY, 2003, p. 73-75).

Para uma época de educação tão conservadora, na qual Vygotsky viveu, acredita-se que ele escandalizava o meio acadêmico ao valorizar tanto a experiência pessoal do educando. Ao defender a educação pela experiência, Vygotsky (2003) associa a ação da criança aos movimentos realizados por ela, e a importância destes para a sua educação:

Em síntese, Vygotsky atribui os movimentos à influência do meio social para a educação do sujeito. Porque tais movimentos representarão a interação do meio social. Assim, quaisquer que sejam os movimentos, eles influenciam a educação do indivíduo.

Considerando essas ideias, pode-se afirmar que a escrita dos professores nos ambientes virtuais como Google Drive, e-mail, WhatsApp, etc., representam um movimento real e social para cada professor participante da formação continuada no âmbito da escola citada.

$\mathrm{O}$ adulto e a criança em determinado momento do desenvolvimento do conhecimento por meio de uma atividade ou experimentação de algo novo a seus olhos, necessita da ajuda de alguém que já conhece aquele objeto a ser estudado. Portanto, segundo Vygotsky (1991) a Zona 


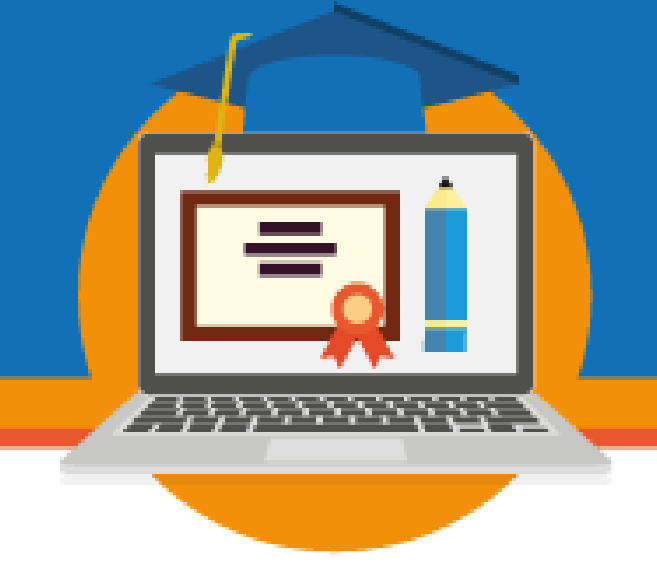

de desenvolvimento próximo desempenha um papel fundamental nessa aprendizagem, pois o aprendiz necessita da mediação de uma pessoa que já conheça o objeto a ser estudado. E que desempenhe a função de mediador buscando facilitar e aprimorar novos conhecimentos por meio das tecnologias.

Esse método tem sido utilizado pela Gestão e Coordenação Pedagógica da Escola Municipal Prof. Licurgo de Oliveira Bastos. A aprendizagem tem sido alcançada por docentes que utilizam os recursos tecnológicos como Google Drive, e-mail, WhatsApp, entre outros, os quais são disponibilizados pela gestão da EM. Prof. Licurgo. Nesses momentos de formação continuada desse grupo escolar, cada participante, professor, coordenador e até mesmo os gestores buscam parceiros entre seus pares, dentro da própria escola e na Secretaria de Educação do Município.

\section{ANÁlises do USO dOS RECURSOS TECNOLÓGICOS NA E. M. PROF.}

\section{LICURGO}

No aspecto geral, o presente relato parte da observação e das expectativas de pesquisa na EM Prof. Licurgo de Oliveira Bastos, as quais mostraram que a escola tem um papel fundamental na vida profissional, tanto dos alunos quanto do grupo escolar docente, que almeja, por meio das ferramentas tecnológicas, chegar à excelência na educação. A partir dessas perspectivas, a escola planeja e disponibiliza a formação continuada dos professores, incentivando-os a usufruírem de todas as possibilidades que a tecnologia oferece no planejamento das aulas e nas atividades a serem desenvolvidas com os educandos. Por conseguinte, as ferramentas tecnológicas foram inseridas no planejamento do professor, e assim, o educador terá mais tempo para estudar e compartilhar com seus colegas o conhecimento científico adquirido.

Portanto, a maneira de ensinar e planejar pede mudanças, na referida escola que busca disponibilizar meios para que o educador possa desempenhar seu fazer pedagógico, bem como, 


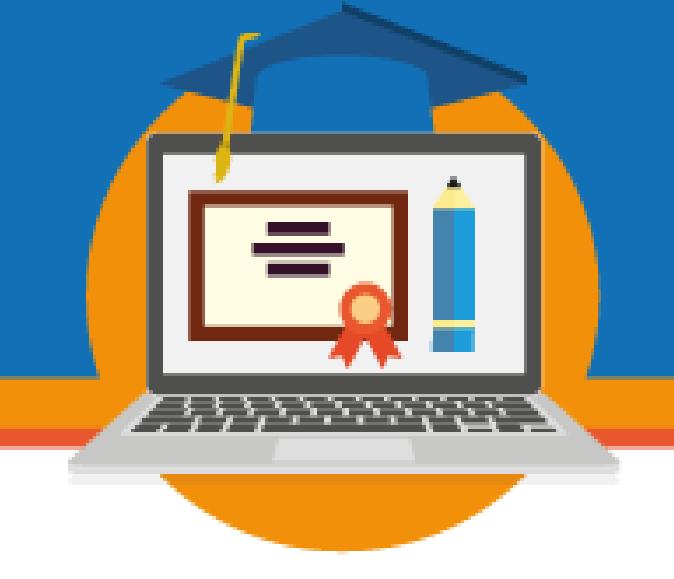

os laboratórios de ciências, matemática, informática e outros recursos que a escola possui, como caixa de som, datashow, notebook, microfone, tablet, entre outros.

Verificou-se que a conexão com a Internet deve ser melhorada para que esse planejamento das aulas, a formação continuada dos professores e dos demais membros da escola, bem como, o desenvolvimento das atividades com os alunos aconteçam em loco.

A Escola Municipal Prof. Licurgo de Oliveira Bastos dialoga e conta com a parceria da Secretaria da Educação do Município. Esta interação tem ocorrido possibilitando a melhoria e implantação de projetos pedagógicos com o uso das tecnologias a fim de alcançar mudanças nos fazeres pedagógicos, e contribuir para o efetivo ensino e aprendizagem de estudantes e professores, como da própria coordenação pedagógica e gestão escolar.

\section{CONCLUSÃO}

O relato aqui discutido e apresentado possui duas funções básicas e relevantes para o contexto educacional, a saber; primeiramente serve como uma reflexão para os próprios professores que escrevem esse trabalho e estão inseridos no cotidiano da escola Prof. Licurgo, e por fim, expande-se como material de pesquisa para acadêmicos e demais professores enquanto contribuição para aqueles que terão acesso a esse trabalho, no sentido de tomarem conhecimento das metodologias de utilização das tecnologias como WhatsApp, Moodle, e-mail e Google Drive nas atividades cotidianas escolares.

Espera-se ainda, que as discussões apresentadas também venham a compor projetos de pesquisa para cursos de pós-graduação tanto em nível lato sensu quanto em nível stricto sensu; seja de professores ou não, da escola mencionada e que almejam aprofundar os seus conhecimentos sobre o uso dos recursos tecnológicos analisados.

Que os órgãos governamentais e municipais continuem apoiando e investindo recursos nas formações continuadas de professores e de coordenadores da escola relatada e que a educação não apenas municipal, como também a estadual e brasileira seja efetiva e atinja o 


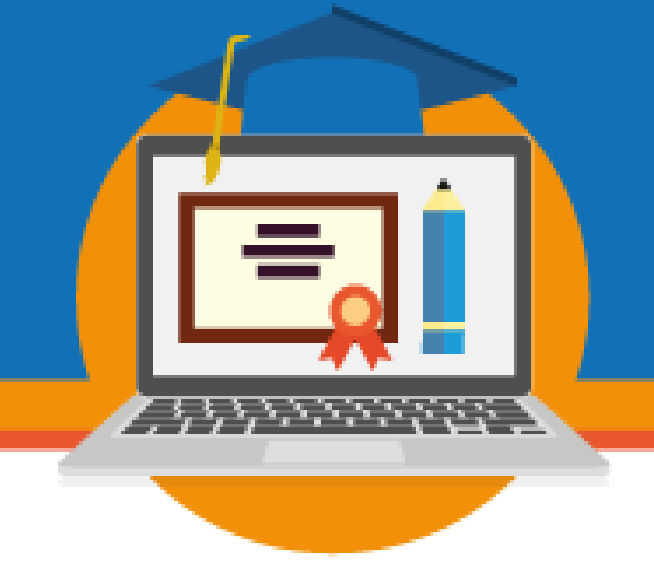

objetivo constitucional brasileiro de formar cidadãos conscientes de seu papel social e transformador da sociedade brasileira.

\section{REFERÊNCIAS}

BATISTA, Erlinda. M e GOBARA, Shirley. T. (2015). Interação na pedagogia a distância de uma instituição pública brasileira. Revista Interacções no. 37, pp.124-149(2015). Disponível em: http://revistas.rcaap.pt/interaccoes/article/view/8469/6044. Acesso em 13 de fevereiro/2018.

BALBINO, Bruna Lusa; HOMRICH, Émerson Pinto; FENNER, Jorge; MACHADO, Josué Furlan; STEFFENELLO, Leonardo Cancian; CASSEL, Otávio Bergamann. Tutorial Google Drive. Centro de Tecnologia Programa de Educação Tutorial - Sistema de Informação. Disponível em: http://coral.ufsm.br/pet-si/wp-content/uploads/2016/04/Consult\%C3\%B3riode-Software-Google-Drive.pdf - Acesso em 21 jan de 2018.

FREITAS, Maria. T. de A. Janela sobre a utopia: Computador e Internet a partir do olhar da abordagem Histórico-Cultural. Artigo apresentado na $32^{\mathrm{a}}$ reunião anual da ANPED em out/2009. Disponível em:

$<\mathrm{http}$ //www.anped.org.br/reunioes/32ra/arquivos/trabalhos/GT16-5857--Int.pdf $>$. Acesso $\mathrm{abr} / 2011$.

.Computador/Internet como instrumentos de aprendizagem: uma reflexão a partir da abordagem psicológica histórico-cultural. Artigo apresentado no $2^{\circ}$ Simpósio Hipertexto e Tecnologias na Educação - Multimodalidade e Ensino. $1^{a}$ Edição UFPE. Recife, 2008. Disponível em: <http://www.ufpe.br/nehte/simposio2008/anais/Maria-TeresaFreitas.pdf $>$ Acesso mar/2013.

.A abordagem sócio-histórica como orientadora da Pesquisa Qualitativa. Cadernos de Pesquisa n ${ }^{\circ} 116$, p. 21-39, julho/2002. Disponível em: $<$ http://www.scielo.br/pdf/cp/n116/14397.pdf $>$. Acesso dez/2012. 


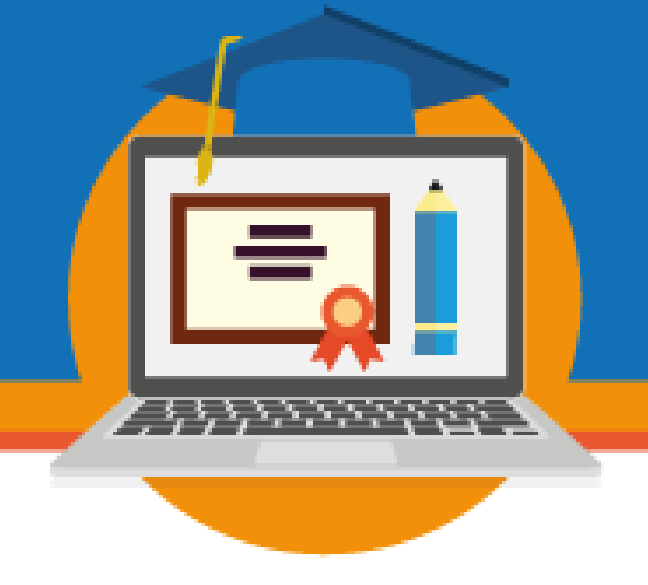

KENSKI, Vani. M. Educação e tecnologias: o novo ritmo da informação. Campinas: Editora Papirus. 2012.

LÜDKE, Menga e ANDRÉ, Marli E. D. A. Pesquisa em educação: abordagens qualitativas. São Paulo: EPU, 1986.

MORETTINI, Marli. T, URT, S. Cancioneiro do Pantanal. Life editora. Campo Grande, 2010 .

NAKAMURA, Rodolfo. Moodle: como criar um curso usando a plataforma de Ensino à Distância. São Paulo: Farol do Forte, 2009.

SANTOS, Milton. Técnica Espaço e tempo. Globalização e o Meio Técnico-Científico Informacional. $3^{\circ}$ Ed. São Paulo Ed. Hucitec, 1997.

SEVERINO, Antônio Joaquim. Metodologia do trabalho científico. 23. Ed. Ver. E atual. São Paulo: Cortez, 2007.

TUSSI, Alessandra Colla Soletti. e-mail como instrumento pedagógico para promover o progresso dos alunos em um curso de inglês online. São Paulo, 2006.

VYGOTSKY, Lev. S. Formação social da mente. Tradução: J. C. Neto, L. S. M. Barreto, S. C. Afeche. $6^{a}$ edição. São Paulo: Martins Fontes, 2002.

Edição online de Formação Social da Mente. (1991).

Disponível em: http://www.egov.ufsc.br/portal/sites/default/files/vygotsky-a-formac3a7c3a3osocial-da-mente.pdf Acesso em 08 março/2016.

Psicologia Pedagógica. Edição comentada. Tradução de Cláudia Shilling. Editora Artmed. São Paulo, 2003.

A construção do Pensamento e da Linguagem. Tradução de Paulo Bezerra.

Martins Fontes, São Paulo, 2001. 


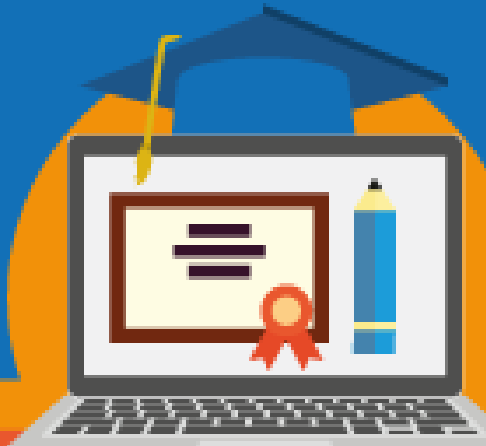

II SEMINÁRIO DE EDUCAÇÃO A DISTÂNCIA

EaD na região Centro-Oeste: Institucionalização, Limites e Potencialidades

12 a 14 de abril de 2018 - Campo Grande/MS 